\title{
Effects of individual and population parameters on reproductive success in three sexually deceptive orchid species
}

\author{
S. Vandewoestijne ${ }^{1}$, A. S. Róis ${ }^{2}$, A. Caperta ${ }^{2,3}$, M. Baguette ${ }^{4}$ \& D. Tyteca ${ }^{1}$ \\ 1 Biodiversity Research Centre, Université catholique de Louvain, Louvain-la-Neuve, Belgium \\ 2 Universidade Lusófona de Humanidades e Tecnologias, Lisboa, Portugal \\ 3 Centro de Botânica Aplicada à Agricultura, Instituto Superior de Agronomia, Lisboa, Portugal \\ 4 Muséum National d'Histoire Naturelle, UMR CNRS 7179, Brunoy, France
}

\author{
Keywords \\ Individual, population and environmental \\ parameters; Ophrys; pollinator limitation; \\ reproductive success; sexually deceptive \\ orchids. \\ Correspondence \\ D. Tyteca, Biodiversity Research Centre, \\ Université catholique de Louvain, B-1348 \\ Louvain-la-Neuve, Belgium. \\ E-mail: daniel.tyteca@uclouvain.be \\ Editor \\ M. Ayasse \\ Received: 27 January 2008; Accepted: 28 \\ May 2008 \\ doi:10.1111/j.1438-8677.2008.00125.x
}

\begin{abstract}
Reproductive success (RS) in orchids in general, and in non-rewarding species specifically, is extremely low. RS is pollinator and pollination limited in food deceptive orchids, but this has rarely been studied in sexually deceptive orchid species. Here, we tested the effects of several individual (plant height, inflorescence size, nearest neighbour distance and flower position) and population (patch geometry, population density and size) parameters on RS in three sexually deceptive Ophrys (Orchidaceae) species. Inter-specific differences were observed in RS of flowers situated in the upper versus the lower part of the inflorescence, likely due to species-specific pollinator behaviour. For all three species examined, RS increased with increasing plant height, inflorescence size and nearest neighbour distance. RS generally increased with decreasing population density and increasing patch elongation. Given these results, we postulate that pollinator availability, rather than pollinator learning, is the most limiting factor in successful reproduction for sexually deceptive orchids. Our results also suggest that olfactory 'display' (i.e. versus optical display), in terms of inflorescence size (and covarying plant height), plays a key role in individual RS of sexually deceptive orchids. In this regard, several hypotheses are suggested and discussed.
\end{abstract}

\section{INTRODUCTION}

The Orchidaceae is one of the largest plant families and represents about $7-10 \%$ of all flowering plants (Dressler 1993). This great diversity is often attributed to adaptive radiation for specific pollinators driven by selection for outcrossing. A recent review of orchid reproductive success by Tremblay et al. (2005) led them to postulate that, with the exception of autogamous species, the low reproductive success of orchids may account for both their unique pollination mechanisms and extreme diversity. Although many orchids provide a reward, nearly onethird of all orchids have a specialised pollination system that works by deceit, i.e. the flowers offer no reward at all (van der Pijl and Dodson 1966; Nilsson 1992), which may indeed be a factor driving radiation (Cozzolino \&
Widmer 2005). Within the orchids, fruit set is higher in rewarding versus non-rewarding or deceiving species (Neiland \& Wilcock 1998; Tremblay et al. 2005). The low reproductive success observed in orchids is pollinator and pollination limited rather than resource limited, as demonstrated in numerous studies through hand-pollination (see review in Calvo 1990, 1993; Wilcock \& Neiland 2002; Tremblay et al. 2005). Given these facts, it remains an enigma why deceptive pollination constitutes an 'evolutionary stable strategy' (Jersáková et al. 2006).

Reproductive success remains low even though many of these non-rewarding pollination-limited orchids have evolved floral traits that appear to maximise pollination success, including increased floral longevity and long-lived pollen (Neiland \& Wilcock 1995). Additionally, deceptive orchids have evolved far-reaching and species-specific 
floral morphological modifications so as to optimise pollinator attractiveness (Nilsson 1992). This is especially true within the Ophrys genus, where the pollinating insects are fooled into 'pseudocopulating' with the flowers, resulting in pollination. All species of this genus have a sexual mimicry pollination system and resemble female insects both chemically and visually. For example, flowers of Ophrys sphegodes produce the same chemical compounds and in similar relative proportions as those found in the sex pheromone of its pollinator species Andrena nigroaenea (Schiestl et al. 1999).

Reproductive success in non-rewarding flowers is further limited by pollinators learning to avoid them. For example, bumblebees flew shorter sequences and longer distances between visits to non-rewarding versus nectarrewarding flowers (Dukas \& Real 1993), greatly decreasing the probability of pollination of the non-rewarding flowers. Orchids, including Orchis and Ophrys, have developed several mechanisms to avoid learning in their pollinators through both intra- and inter-plant variations in pollinator attracting olfactory recognition signals (Ayasse et al. 2000; Salzmann et al. 2007). Additionally, reproductive success is maximised in Ophrys species through post-pollination alteration of fragrances. Following pollination, there is a general decrease in odour production accompanied by increased production of farnesyl hexanoate, a substance signalling unreceptive breeding females (Schiestl \& Ayasse 2001), thereby redirecting subsequent male pollinators to unpollinated flowers of the inflorescence. Despite these numerous traits, reproductive success in Ophrys species, as measured by fruit set, remains exceptionally low, as demonstrated in O. sphegodes (where only $4.9 \%$ of plants were visited by a pollinator, Ayasse et al. 2000) and other Ophrys species (e.g. Kullenberg 1950; Neiland \& Wilcock 1998; Tremblay et al. 2005).

The influence of environmental, population and individual factors on reproductive success has been extensively studied in numerous non-rewarding species. Nonrewarding species may be dependent on other species in the community to provide rewards (Wilcock \& Neiland 2002). Aside from the community species composition, increased population size of the non-rewarding species itself is often, but not always, associated with increased pollination success (e.g. Jacquemyn et al. 2002; Kropf \& Renner 2005; Tremblay et al. 2005). This is generally assumed to be due to an increase in pollinator abundance through increased patch visibility and attractiveness. However, an increase in population density often results in a decrease in individual reproductive success (Jacquemyn et al. 2002; Tremblay et al. 2005), interpreted as a consequence of insect learning and subsequent negative frequency-dependent selection (the higher the level of aggregation of rewardless plants, the more often pollinators encounter them and the faster they may learn to avoid them (Internicola et al. 2006). Pollinator limitation may also result in a negative relationship between population size and pollinator visitation rate (e.g. Fritz \& Nilsson 1994). Increased visibility likely explains the positive relationship between individual reproductive success and flower height (O'Connell \& Johnston 1998; Kropf \& Renner 2005) and inflorescence size (i.e. number of flowers, Johnson \& Nilsson 1999), while negative frequencydependent selection may account for decreased reproductive success in late-flowering individuals (decrease in naïve pollinators with season, Johnson \& Nilsson 1999). It has also been suggested that reproductive success within the inflorescence is likely to be highest toward the bottom of the inflorescence and decrease towards the top due to foraging behaviour or the depletion of naive pollinators (Tremblay et al. 2005). Indeed, generally, flowers at the bottom of the inflorescence are the first to open and may therefore benefit from attracting 'inexperienced' or naïve pollinators. Nevertheless, flowers at the bottom of the inflorescence are not characterised by greater longevity and therefore do not necessarily benefit from longer receptive time periods compared with flowers higher up in the inflorescence. However, all of these results are uniquely based on food deceptive orchid species (but see Kindlmann \& Jersáková 2006 for effect of inflorescence size on reproductive success in deceptive orchids), and the effects of these individual plant and population parameters do not necessarily hold for sexually deceptive orchids such as Ophrys species. Undeniably, both pollinator behaviour and movement will differ greatly between foraging (in the case of food deceptive orchids) and mate searching (in the case of sexually deceptive orchids) (Peakall 1990).

We explicitly test the influence of different individual, population and environmental parameters on reproductive success at four different levels in three sexually deceptive species, O. fuciflora, O. insectifera and O. sphegodes. First, due to depletion of naïve pollinators and/or insect learning (Tremblay et al. 2005), we expect that withininflorescence reproductive success will be higher towards the bottom of the inflorescence. However, the probability of insect visitation to a particular flower within an inflorescence may also be highly dependent on the patrolling behaviour of the males. Second, we expect that individual parameters influencing visibility, such as plant height and inflorescence size, will be positively correlated to reproductive success in all three species (i.e. O'Connell \& Johnston 1998; Johnson \& Nilsson 1999), while nearest neighbour distance (or local density) should have the opposite effect as a result of negative frequency-dependent selection. Third, population parameters should have similar effects on reproductive success in the three study species, with decreased population size (or density) and increased patch visibility (related to its geometric configuration) resulting in increased reproductive success due to pollinator limitation (e.g. Jacquemyn et al. 2002; Tremblay et al. 2005) and increased rate in pollinator passages, respectively. Finally, because reproductive success can vary substantially among years (e.g. Wilcock \& Neiland 2002), data were collected for two consecutive years to incorporate annual variation in reproductive success in our analyses. 


\section{MATERIALS AND METHODS}

Species and study sites

Ophrys insectifera (Linné), O. fuciflora (Moench) and O. sphegodes (Miller) are characterised by cephalic pseudocopulation (e.g. Paulus \& Gack 1990). They are widely distributed throughout middle Europe and are the only three allogamous Ophrys species that grow in the study region. The only other species present within this study region, O. apifera, is autogamous. Ophrys insectifera is a highly distinct and morphologically stable species; it is pollinated by solitary wasps of the genus Argogorytes (A. mystaceus, A. fargei; van der Cingel 1995). Ophrys fuciflora and O. sphegodes belong to complex species groups, characterised by considerable variations and intense radiation. They are pollinated by solitary bees, i.e. O. sphegodes by several Andrena species, and O. fuciflora by Eucera species (E. nigrescens, E. longicornis; van der Cingel 1995). The latter is also occasionally pollinated by Coleopterans, e.g. Phyllopertha horticola (Tyteca et al. 2006). Although pollination events by species other than Hymenopterans are observed, they remain rare and are not likely to have any evolutionary significance (Paulus 2006).

Populations were visited at the latest possible stage, i.e. at the end of the flowering period (May and June in both 2005 and 2006 whenever possible), to ensure that all pollination events were accounted for (Table 1). Study site localities, all situated in southern Belgium and northern France, and characteristics are summarised in Table 1. Three populations in Bure (No. 9-11) in fact represent three sub-populations within the same locality, separated from each other, and with somewhat different microclimatic conditions. The habitats were mainly chalk grasslands with a rich flora, located below $300 \mathrm{~m}$, and characterised by similar slopes (with the exception of Givet) and solar exposure. To control for inter-annual variation in pollination success, weather data (duration of daily sunshine and temperature) were collected from weather stations (IRM, Institut Royal Météorologique de Belgique) near the study sites. Whenever pollinators were sighted, behavioural interactions with the Ophrys species were noted.

Table 1. Population and site characteristics.

\begin{tabular}{|c|c|c|c|c|c|c|c|c|c|c|}
\hline species & $\begin{array}{l}\text { locality } \\
\text { (Prov/Dept, Country) }\end{array}$ & habitat & $\begin{array}{l}\text { coordinates } \\
\text { long } E \text {, lat } N\end{array}$ & $\begin{array}{l}\text { altitude } \\
\text { (m) }\end{array}$ & $\begin{array}{l}\text { slope, } \\
\text { exposure }\end{array}$ & year & $n$ & $\begin{array}{l}\text { patch } \\
\text { geometry }\end{array}$ & density & RS \% \\
\hline \multirow{8}{*}{$\begin{array}{l}\text { Ophrys } \\
\text { fuciflora }\end{array}$} & \multirow[t]{2}{*}{ Givet, France } & \multirow{2}{*}{$\begin{array}{l}\text { Chalk grassland } \\
\text { with shrubs }\end{array}$} & $4^{\circ} 47^{\prime} 14^{\prime \prime}$ & \multirow[t]{2}{*}{$120-140$} & \multirow[t]{2}{*}{$20-50^{\circ}, \mathrm{SW}$} & 2005 & 82 & 0.786 & 0.027 & 11.24 \\
\hline & & & $50^{\circ} 07^{\prime} 00^{\prime \prime}$ & & & 2006 & 62 & 0.786 & 0.021 & 3.12 \\
\hline & \multirow{2}{*}{$\begin{array}{l}\text { Lavaux-Ste-Anne, } \\
\text { Belgium }\end{array}$} & \multirow{2}{*}{$\begin{array}{l}\text { Chalk grassland } \\
\text { with bushes }\end{array}$} & $5^{\circ} 05^{\prime} 53^{\prime \prime}$ & \multirow[t]{2}{*}{190} & \multirow[t]{2}{*}{$15^{\circ}, \mathrm{SSW}$} & 2005 & 9 & 0.628 & 0.389 & 19.44 \\
\hline & & & $50^{\circ} 06^{\prime} 23^{\prime \prime}$ & & & 2006 & 37 & 0.611 & 0.762 & 3.69 \\
\hline & \multirow[t]{2}{*}{ Nismes, Belgium } & \multirow{2}{*}{$\begin{array}{l}\text { Open chalk } \\
\text { grassland }\end{array}$} & $4^{\circ} 32^{\prime} 43^{\prime \prime}$ & \multirow[t]{2}{*}{200} & \multirow[t]{2}{*}{$10-15^{\circ}, \mathrm{S}$} & 2005 & 46 & 0.826 & 1.219 & 0 \\
\hline & & & $50^{\circ} 04^{\prime} 40^{\prime \prime}$ & & & 2006 & 82 & 0.665 & 1.670 & 0.56 \\
\hline & \multirow[t]{2}{*}{ St-Thomas, France } & \multirow{2}{*}{$\begin{array}{l}\text { Open, pastured } \\
\text { chalk grassland }\end{array}$} & $3^{\circ} 49^{\prime} 22^{\prime \prime}$ & \multirow[t]{2}{*}{190} & \multirow[t]{2}{*}{$20^{\circ}, \mathrm{S}$} & 2005 & 66 & 0.986 & 0.185 & 3.78 \\
\hline & & & $49^{\circ} 30^{\prime} 12^{\prime \prime}$ & & & 2006 & 79 & 0.674 & 0.797 & 1.77 \\
\hline \multirow{11}{*}{$\begin{array}{l}\text { Ophrys } \\
\text { insectifera }\end{array}$} & \multirow[t]{2}{*}{ Ave, Belgium } & \multirow{2}{*}{$\begin{array}{l}\text { Chalk grassland } \\
\text { (old quarry) }\end{array}$} & $5^{\circ} 08^{\prime} 09^{\prime \prime}$ & \multirow[t]{2}{*}{225} & \multirow[t]{2}{*}{$5^{\circ}, \mathrm{SSW}$} & 2005 & 46 & 0.439 & 1.391 & 11.08 \\
\hline & & & $50^{\circ} 05^{\prime} 59^{\prime \prime}$ & & & 2006 & 66 & 0.592 & 0.620 & 6.98 \\
\hline & \multirow[t]{2}{*}{ Branscourt, France } & \multirow{2}{*}{$\begin{array}{l}\text { Chalk grassland } \\
\text { with trees }\end{array}$} & $3^{\circ} 48^{\prime} 41^{\prime \prime}$ & \multirow[t]{2}{*}{140} & \multirow{2}{*}{$\begin{array}{l}5-10^{\circ} \\
\text { changing }\end{array}$} & 2005 & 52 & 0.502 & 0.314 & 2.39 \\
\hline & & & $49^{\circ} 16^{\prime} 41^{\prime \prime}$ & & & 2006 & 58 & 0.429 & 0.449 & 0.60 \\
\hline & \multirow{5}{*}{ Bure, Belgium } & \multirow{5}{*}{$\begin{array}{l}\text { Chalk grassland } \\
\text { (old quarry), } \\
\text { three } \\
\text { separated } \\
\text { sub-populations }\end{array}$} & $50^{\circ} 06^{\prime} 06^{\prime \prime}$ & 1 & $0-5^{\circ}, \mathrm{s}$ & 2006 & 53 & 0.527 & 0.389 & 9.59 \\
\hline & & & $5^{\circ} 14^{\prime} 45^{\prime \prime}$ & \multirow[t]{2}{*}{2} & $0^{\circ}$ & 2005 & 9 & 0.814 & 0.191 & 26.52 \\
\hline & & & $50^{\circ} 06^{\prime} 07^{\prime \prime}$ & & & 2006 & 11 & 0.293 & 0.488 & 11.67 \\
\hline & & & $5^{\circ} 14^{\prime} 44^{\prime \prime}$ & 3 & $30-40^{\circ}$ NNE & 2005 & 47 & 0.235 & 0.464 & 40.72 \\
\hline & & & $50^{\circ} 06^{\prime} 06^{\prime \prime}$ & & & 2006 & 99 & 0.078 & 0.300 & 23.43 \\
\hline & $\begin{array}{l}\text { Lavaux-Ste-Anne, } \\
\text { Belgium }\end{array}$ & $\begin{array}{l}\text { Open chalk } \\
\text { grassland }\end{array}$ & $\begin{array}{l}5^{\circ} 05^{\prime} 58^{\prime \prime} \\
50^{\circ} 06^{\prime} 23^{\prime \prime}\end{array}$ & 190 & $15^{\circ}, \mathrm{S}$ & 2006 & 78 & 0.423 & 0.054 & 7.43 \\
\hline & St-Thomas, France & $\begin{array}{l}\text { Open, pastured } \\
\text { chalk grassland }\end{array}$ & $\begin{array}{l}3^{\circ} 49^{\prime} 21^{\prime \prime} \\
49^{\circ} 30^{\prime} 12^{\prime \prime}\end{array}$ & 190 & $20^{\circ}, \mathrm{S}$ & 2006 & 16 & 0.350 & 0.236 & 12.88 \\
\hline Ophrys & Bourg-et-Comin, & Chalk grassland & $3^{\circ} 39^{\prime} 04^{\prime \prime}$ & 140 & $0^{\circ}$ & 2005 & 45 & 0.170 & 0.958 & 3.33 \\
\hline sphegodes & France & with sand & $49^{\circ} 24^{\prime} 14^{\prime \prime}$ & & & 2006 & 44 & 0.248 & 0.218 & 2.65 \\
\hline & St-Thomas, France & Open, pastured & $3^{\circ} 49^{\prime} 20^{\prime \prime}$ & 190 & $20^{\circ}, \mathrm{S}$ & 2005 & 11 & 0.139 & 0.028 & 51.67 \\
\hline & & chalk grassland & $49^{\circ} 30^{\prime} 12^{\prime \prime}$ & & & 2006 & 15 & 0.162 & 0.022 & 38.33 \\
\hline & Velosnes, France & Chalk grassland & $\begin{array}{l}5^{\circ} 27^{\prime} 16^{\prime \prime} \\
49^{\circ} 30^{\prime} 00^{\prime \prime}\end{array}$ & 275 & $20^{\circ}, \mathrm{SSE}$ & 2005 & 66 & 0.717 & 1.044 & 2.83 \\
\hline & Inor, France & Chalk grassland & $\begin{array}{l}5^{\circ} 10^{\prime} 05^{\prime \prime} \\
49^{\circ} 33^{\prime} 18^{\prime \prime}\end{array}$ & 260 & $30^{\circ}, \mathrm{SE}$ & 2005 & 54 & 0.713 & 0.446 & 3.43 \\
\hline
\end{tabular}

$\mathrm{N}=$ population size (number of individuals); patch geometry = patch width divided by length; density = number of flowering individuals per square meter; reproductive success (RS) \% = population average of individual RS (number of pollinated flowers/total number of flowers). 


\section{Data collection}

Individual reproductive success (RS) was approximated as the number of fruits (i.e. inflated capsules per inflorescence) and capsule set (ratio of pollinated flowers or inflated capsules divided by the total number of flowers in a given inflorescence). The nearest neighbour distance (NND, i.e. shortest distance to the nearest flowering individual), plant height, inflorescence size (i.e. number of flowers per inflorescence including buds, open and wilted flowers) were measured in every population. NND, the local density, was log-transformed because of its clearly asymmetric distribution in all populations; i.e. with many individuals having their nearest neighbour in close proximity (low NND) and only a few isolated individuals with no immediate neighbour (large NND). This type of distribution likely results from occupation of the optimal habitat by numerous individuals, i.e. high density towards the centre of the population, and more isolated location of individual plants towards the population periphery. Population parameters included population size (number of flowering individuals), population density (number of flowering individuals per square meter) and patch geometry (width divided by length). The latter parameter was included because a potentially larger number of insects are likely to encounter patch boundaries (and consequently immigrate into or emigrate out of the patch) when the perimeter increases.

\section{Data analyses}

In order to test for position-dependent pollination success (i.e. within an inflorescence), RS was divided into two groups (i) lower inflorescence RS (RSlower), i.e. inflated capsules below the middle of the inflorescence, and (ii) upper inflorescence RS (RSupper), i.e. inflated capsules above the middle of the inflorescence. A paired $t$-test was carried out on the entire dataset (populations and years combined).

Significance of individual variables (inflorescence size, plant height and NND) affecting RS was tested by subdividing the data into two subsets: (i) success (plants with RS greater than zero) versus failure (plants with no RS) to analyse reproductive success versus reproductive failure, and (ii) RS between plants with a RS greater than zero to analyse causal effects in multiple successful pollination events. This was necessary because of the very high proportion of non-pollinated plants observed in the study. Generalised linear models were used to assess the relationship of RS to the explanatory variables with the SAS GENMOD procedure with a logit link function and binomial distribution (for the success versus failure subset) or an identity link function and normal distribution (for the RS greater than zero subset). When two or more explanatory variables were not independent, i.e. significantly correlated (Pearson's correlation coefficient), a principal component analysis (PCA) was used to represent the variation. To allow for discrete independent effects between population and years, a 'population-year' variable was created (classification variable). Although this leads to a loss of information, it increases the statistical power of the analyses. Interactions between the explanatory and classification variables were included in the generalised linear models (GLMs) to test for changes in the relationship between the dependent and explanatory variables by the classification variable. For all analyses, all possible explanatory variables and their interactions were modelled. Type III sum of squares was used to test significance of explanatory and classification variables. Akaike's Information Criterion (AIC) was used to select the best model (that with the lowest AIC value). AIC represents the trade-off between the fit of the model (adjustment to data) and its complexity (number of parameters), and was calculated as follows:

$$
\mathrm{AIC}=-2 \ln [\mathrm{L}(\theta)]+2 \mathrm{~K}
$$

where $\mathrm{L}(\theta)$ represents the likelihood of the model and $\mathrm{K}$, the number of parameters in the model (Akaike 1973).

At the population level, RS was calculated as the percentage of pollinated flowers divided by the total number of flowers (all individuals combined). This dependent variable was regressed against patch geometry and population size and density using the GENMOD procedure, with year as classification variable. Population size and density and patch geometry were log-transformed to approach a normal distribution. Population size and population density were highly correlated for all three species; therefore, regressions were carried out separately with population density and population size. Only the former is discussed, since density gave the models with the best fit. Model selection was again based on AIC values.

For inter-annual variations in RS, only populations sampled in both 2005 and 2006 were considered in the $t$-test analyses. Due to increased variance with increased RS, RS was log-transformed. Daily sunshine and temperature were also compared between years for O. fuciflora and $O$. insectifera (no precise data were available for the O. sphegodes field stations). All statistical analyses were performed in SAS 9.1 (SAS Institute, Cary, NC, USA).

\section{RESULTS}

Measures of capsule set and number (RS), NND, inflorescence size, plant height, population size and density and patch geometry are summarised in Table 1. RS was low and highly variable between populations and years, ranging between $0-19.44 \%$ pollinated flowers in O. fuciflora (mean: $4.26 \pm 0.71 \%$ ), $0.60-40.72 \%$ pollinated flowers in O. insectifera (mean: $13.79 \pm 1.31 \%$ ) and $2.65-51.67 \%$ pollinated flowers in O. sphegodes (mean: $8.92 \pm 2.09 \%$ ).

\section{Pseudocopulation in Ophrys populations}

Only seven pseudocopulatory events by pollinating insects, in 2784 flowers from the 581 surveyed Ophrys 
plants, were observed during the 2005 field season. Three of these pseudocopulations were performed by Hymenopterans (two Argogorytes mystaceus on O. insectifera and one Eucera sp. on O. fuciflora), and the remaining four by a Coleopteran, namely Phyllopertha horticola on $\mathrm{O}$. fuciflora (Tyteca et al. 2006). No pseudocopulatory events were observed during the 2006 field season (3664 flowers from 700 plants).

\section{Within inflorescence reproductive success}

For both O. fuciflora and O. sphegodes, flowers from the lower part of the inflorescence set more seeds than flowers from the upper part of the inflorescence $(t$-value $=4.18, \quad \mathrm{P}<0.0001, \quad \mathrm{df}=70 \quad$ and $t$-value $=2.4$, $\mathrm{P}=0.0211, \mathrm{df}=42$, respectively). Ophrys insectifera, on the other hand, had a significantly greater RSupper than RSlower $(t$-value $=-2.62, \mathrm{P}=0.0094, \mathrm{df}=224)$.

\section{Inter-individual variation in reproductive success}

Individual plant parameters for all three species are summarised in Table 2. In Ophrys fuciflora, plant height, inflorescence size and $\log (\mathrm{NND})$ were all significantly correlated. Two PCA axes were retained, the first (positively correlated to all three variables) explaining $57.24 \%$ of the variation, the second (negatively correlated to plant height and inflorescence size, positively correlated to NND) explaining $31.61 \%$ of the variation (Table 3). For the success versus failure dataset, the GLM model (Table 4) with the lowest AIC retained the first axis, suggesting that the probability of at least one successful pollination event (RS $>$ zero) increased with inflorescence size, height and NND. There was a significant population-year effect, implying that RS varied significantly, but in a similar manner (no interaction effect), between populations and years. Similar results were found within

Table 2. Individual plant parameters and reproductive success averaged over populations.

\begin{tabular}{|c|c|c|c|c|c|c|}
\hline species & year & locality & $\mathrm{NND}(\mathrm{m})$ & number of flowers & plant height $(\mathrm{cm})$ & RS number \\
\hline \multirow{11}{*}{$\begin{array}{l}\text { Ophrys } \\
\text { fuciflora }\end{array}$} & \multirow[t]{5}{*}{2005} & Givet & $0.64 \pm 0.82(0.01-3.75)$ & $4.60 \pm 2.13(1-13)$ & $20.76 \pm 6.26(8.0-42.5)$ & $0.59 \pm 1.01(0-5)$ \\
\hline & & Lavaux-Ste-Anne & $1.01 \pm 1.03(0.36-3.15)$ & $5.44 \pm 1.13(4-8)$ & $26.94 \pm 6.68(17.0-35.7)$ & $1.11 \pm 1.17(0-3)$ \\
\hline & & Nismes & $0.29 \pm 0.38(0.01-1.62)$ & $3.57 \pm 1.29(1-7)$ & $10.89 \pm 3.43(5.9-21.3)$ & $0 \pm 0(0)$ \\
\hline & & St-Thomas & $0.46 \pm 0.66(0.01-3.54)$ & $5.92 \pm 2.47(2-13)$ & $25.33 \pm 7.05(13.5-40.8)$ & $0.27 \pm 0.67(0-4)$ \\
\hline & & average & $0.52 \pm 0.72(0.01-3.75)$ & $4.83 \pm 2.24(1-13)$ & $20.28 \pm 8.16(5.9-42.5)$ & $0.37 \pm 0.83(0-5)$ \\
\hline & \multirow[t]{5}{*}{2006} & Givet & $0.87 \pm 1.41(0.03-9.12)$ & $4.63 \pm 2.09(1-11)$ & $20.23 \pm 6.62(7.1-34.2)$ & $0.15 \pm 0.40(0-2)$ \\
\hline & & Lavaux-Ste-Anne & $0.57 \pm 0.54(0.06-2.84)$ & $5.30 \pm 1.96(3-10)$ & $27.68 \pm 9.78(12.5-46.0)$ & $0.27 \pm 0.56(0-2)$ \\
\hline & & Nismes & $0.24 \pm 0.29(0.00-1.12)$ & $3.98 \pm 1.63(2-8)$ & $17.74 \pm 4.71(8.8-28.4)$ & $0.02 \pm 0.16(0-1)$ \\
\hline & & St-Thomas & $0.26 \pm 0.36(0.01-2.00)$ & $5.32 \pm 2.33(1-13)$ & $20.96 \pm 7.51(5.9-40.6)$ & $0.10 \pm 0.30(0-1)$ \\
\hline & & average & $0.44 \pm 0.80(0.00-9.12)$ & $4.73 \pm 2.09(1-13)$ & $20.73 \pm 7.57(5.9-46.0)$ & $0.11 \pm 0.35(0-2)$ \\
\hline & \multicolumn{2}{|c|}{ global average } & $0.48 \pm 0.76(0.00-9.12)$ & $4.77 \pm 2.15(1-13)$ & 20. $53 \pm 7.83(5.9-46.0)$ & $0.23 \pm 0.62(0-5)$ \\
\hline \multirow{15}{*}{$\begin{array}{l}\text { Ophrys } \\
\text { insectifera }\end{array}$} & \multirow[t]{6}{*}{2005} & Ave & $0.47 \pm 0.45(0.01-1.77)$ & $6.43 \pm 2.31(3-13)$ & $26.49 \pm 9.83(9.8-50.7)$ & $0.89 \pm 1.30(0-5)$ \\
\hline & & Branscourt & $0.69 \pm 0.70(0.01-2.79)$ & $7.62 \pm 2.71(2-14)$ & $43.46 \pm 13.28(16.7-67.5)$ & $0.19 \pm 0.53(0-2)$ \\
\hline & & Bure -1 & $0.60 \pm 1.55(0.02-10.7)$ & $5.33 \pm 1.77(3-10)$ & $20.03 \pm 6.45(8.5-40.0)$ & $0.73 \pm 1.25(0-6)$ \\
\hline & & Bure -2 & $1.66 \pm 1.55(0.17-4.60)$ & $6.67 \pm 2.29(4-12)$ & $23.97 \pm 8.61(18.7-45.7)$ & $2.22 \pm 2.77(0-8)$ \\
\hline & & Bure -3 & $0.53 \pm 0.98(0.02-6.53)$ & $5.15 \pm 1.60(2-9)$ & $24.86 \pm 7.19(8.7-39.0)$ & $2.17 \pm 1.72(0-6)$ \\
\hline & & average & $0.63 \pm 1.05(0.01-10.70)$ & $6.19 \pm 2.36(2-14)$ & $28.83 \pm 13.07(8.5-67.5)$ & $1.03 \pm 1.54(0-8)$ \\
\hline & \multirow[t]{8}{*}{2006} & Ave & $0.49 \pm 0.76(0.00-4.84)$ & $6.08 \pm 1.89(2-11)$ & $27.62 \pm 7.92(15.0-45.1)$ & $0.47 \pm 0.85(0-3)$ \\
\hline & & Branscourt & $0.59 \pm 0.60(0.02-3.09)$ & $6.78 \pm 2.66(2-14)$ & $37.00 \pm 13.06(13.1-67.6)$ & $0.03 \pm 0.18(0-1)$ \\
\hline & & Bure -1 & $0.71 \pm 0.57(0.02-2.57)$ & $5.62 \pm 1.93(2-13)$ & $24.31 \pm 6.76(13.5-45.4)$ & $0.62 \pm 1.11(0-4)$ \\
\hline & & Bure -2 & $1.07 \pm 1.00(0.13-2.89)$ & $5.18 \pm 1.78(3-8)$ & $22.59 \pm 7.07(14.0-36.8)$ & $0.55 \pm 0.82(0-2)$ \\
\hline & & Bure -3 & $0.45 \pm 0.55(0.01-3.32)$ & $5.13 \pm 2.07(1-10)$ & $25.19 \pm 7.86(9.0-50.3)$ & $1.27 \pm 1.44(0-6)$ \\
\hline & & Lavaux-Ste-Anne & $1.22 \pm 2.39(0.01-20.78)$ & $6.38 \pm 2.34(3-14)$ & $25.90 \pm 9.21(13.0-48.7)$ & $0.59 \pm 1.14(0-6)$ \\
\hline & & St-Thomas & $1.10 \pm 1.27(0.01-3.52)$ & $7.38 \pm 2.31(3-10)$ & $29.86 \pm 8.11(13.2-39.5)$ & $1.00 \pm 1.10(0-4)$ \\
\hline & & average & $0.72 \pm 1.27(0.00-20.78)$ & $5.97 \pm 2.26(1-14)$ & $27.55 \pm 9.88(9.0-67.6)$ & $0.68 \pm 1.15(0-6)$ \\
\hline & \multicolumn{2}{|c|}{ global average } & $0.69 \pm 1.20(0.00-20.78)$ & $6.04 \pm 2.30(1-14)$ & $28.00 \pm 11.09(8.5-67.6)$ & $0.80 \pm 1.31(0-8)$ \\
\hline \multirow{9}{*}{$\begin{array}{l}\text { Ophrys } \\
\text { sphegodes }\end{array}$} & \multirow[t]{5}{*}{2005} & Bourg-et-Comin & $0.39 \pm 0.73(0.04-3.68)$ & $2.82 \pm 0.78(1-5)$ & $20.93 \pm 6.04(5.8-29.8)$ & $0.09 \pm 0.36(0-2)$ \\
\hline & & St-Thomas & $2.09 \pm 1.47(0.55-4.45)$ & $3.36 \pm 1.21(2-5)$ & $19.10 \pm 3.47(12.5-25.9)$ & $1.64 \pm 0.92(0-3)$ \\
\hline & & Velosnes & $0.35 \pm 0.46(0.01-2.10)$ & $3.36 \pm 1.44(1-8)$ & $17.27 \pm 5.63(7.4-30.0)$ & $0.12 \pm 0.33(0-1)$ \\
\hline & & Inor & $0.32 \pm 0.39(0.04-2.48)$ & $3.09 \pm 1.05(1-5)$ & $18.05 \pm 5.15(7.4-36.7)$ & $0.13 \pm 0.34(0-1)$ \\
\hline & & average & $0.46 \pm 0.75(0.01-4.45)$ & $3.14 \pm 1.18(1-8)$ & $18.56 \pm 5.64(5.8-36.7)$ & $0.21 \pm 0.54(0-3)$ \\
\hline & \multirow[t]{3}{*}{2006} & Bourg-et-Comin & $1.13 \pm 2.59(0.00-11.88)$ & $2.59 \pm 0.76(1-4)$ & $18.70 \pm 4.50(11.4-32.9)$ & $0.07 \pm 0.25(0-1)$ \\
\hline & & St-Thomas & $3.43 \pm 3.87(0.13-15.24)$ & $3.20 \pm 1.01(2-5)$ & $18.57 \pm 4.10(12.2-26.3)$ & $1.27 \pm 0.96(0-3)$ \\
\hline & & average & $1.72 \pm 3.10(0.00-15.24)$ & $2.75 \pm 0.86(1-5)$ & $18.67 \pm 4.37(11.4-32.9)$ & $0.37 \pm 0.74(0-3)$ \\
\hline & \multicolumn{2}{|c|}{ global average } & $0.78 \pm 1.76(0.00-15.24)$ & $3.04 \pm 1.12(1-8)$ & $18.59 \pm 5.34(5.8-36.7)$ & $0.25 \pm 0.60(0-3)$ \\
\hline
\end{tabular}

NND = nearest neighbour distance; RS number = average number of pollinated flowers per plant, standard deviation and the range in parentheses. 
Table 3. Principal component analyses on individual plant parameters: variation in inflorescence size, plant height and nearest neighbour distance (NND) are summarised into principal components (PCA) when significantly correlated.

\begin{tabular}{llr}
\hline & PCA1 & PCA2 \\
\hline $\begin{array}{l}\text { Ophrys fuciflora } \\
\text { inflorescence size }\end{array}$ & 0.681 & \\
plant height & 0.685 & -0.199 \\
NND & 0.260 & -0.170 \\
Ophrys insectifera & & 0.966 \\
inflorescence size & 0.699 & -0.094 \\
plant height & 0.695 & -0.143 \\
NND & 0.168 & 0.985 \\
Ophrys sphegodes & & \\
inflorescence size & 0.707 & \\
plant height & 0.707 & \\
\hline
\end{tabular}

Table 4. Individual reproductive success (pollinated flower number) in relation to individual plant parameters.

\begin{tabular}{|c|c|c|c|c|}
\hline source & $\begin{array}{l}\text { correlation } \\
\text { coefficient }\end{array}$ & $d f$ & $\chi^{2}$ & $\operatorname{Pr}>\chi^{2}$ \\
\hline \multicolumn{5}{|c|}{$\begin{array}{l}\text { Ophrys fuciflora } \\
\text { reproductive success versus failure }\end{array}$} \\
\hline $\begin{array}{l}\text { PCA1 } \\
\text { population-year }\end{array}$ & 0.71 & $\begin{array}{l}1 \\
7\end{array}$ & $\begin{array}{l}38.53 \\
40.04\end{array}$ & $\begin{array}{l}<0.0001 \\
<0.0001\end{array}$ \\
\hline pollinated flower number & & & & \\
\hline $\begin{array}{l}\text { PCA1 } \\
\text { population-year }\end{array}$ & 0.27 & $\begin{array}{r}\text { df } \\
6\end{array}$ & $\begin{array}{l}15.73 \\
20.28\end{array}$ & $\begin{array}{r}<0.0001 \\
0.0025\end{array}$ \\
\hline \multicolumn{5}{|c|}{$\begin{array}{l}\text { Ophrys insectifera } \\
\text { reproductive success versus failure }\end{array}$} \\
\hline PCA1 & 3.76 & 1 & 52.46 & $<0.0001$ \\
\hline population-year & & 11 & 132.13 & $<0.0001$ \\
\hline PCA 1 *Population-year & & 11 & 23.08 & 0.0172 \\
\hline PCA2 & -6.51 & 1 & 2.36 & 0.1242 \\
\hline PCA2* population-year & & 11 & 35.53 & 0.0002 \\
\hline PCA1*PCA2 & & 1 & 6.67 & 0.0098 \\
\hline \multicolumn{5}{|l|}{ pollinated flower number } \\
\hline PCA1 & 0.62 & 1 & 35.3 & $<0.0001$ \\
\hline PCA2 & -0.14 & 1 & 5.59 & 0.0181 \\
\hline population-year & & 11 & 59.57 & $<0.0001$ \\
\hline PCA1*Population-year & & 11 & 27.33 & 0.0041 \\
\hline \multicolumn{5}{|c|}{$\begin{array}{l}\text { Ophrys sphegodes } \\
\text { reproductive success versus failure }\end{array}$} \\
\hline PCA1 & 0.74 & 1 & 17.31 & $<0.0001$ \\
\hline $\begin{array}{l}\text { population-year } \\
\text { pollinated flower number }\end{array}$ & & 5 & 70.35 & $<0.0001$ \\
\hline PCA1 & 0.23 & 1 & 6.89 & 0.0087 \\
\hline population-year & & 5 & 20.09 & 0.0012 \\
\hline
\end{tabular}

AIC = Akaike's Information Criterion; PCA = principal component analysis.

Inflorescence size, plant height and nearest neighbour distance (NND) are summarised in PCA components. For each of the three species, the model with the lowest AIC (best fit) is shown. Reproductive success was modelled with (i) reproductive success (RS $>0$ ) versus failure $(\mathrm{RS}=0)$ data and (ii) pollinated flower number data (RS $>0$ ). the 'RS greater than zero' subset where the selected model included the first PCA axis and the population-year variable. RS, expressed as the number of pollinated flowers per plant, increased with height, number of flowers and NND (Table 4).

In O. insectifera, as in O. fuciflora, the three explanatory variables were summarised into two PCA axes because of their highly significant correlations $(\mathrm{PCA} 1=58.58 \%, \quad$ PCA $2=32.63 \%$; Table 3$)$. For both data subsets, both PCA1 and PCA2 explained variation in RS. Yet again, an increase in inflorescence size and plant height increased the probability of at least one pollination (success versus failure dataset), as well as enhancing total RS (number of flowers pollinated per inflorescence). Since NND is positively correlated to PCA1 and PCA2 (and the regression coefficient for PCA1 was positive, and negative for PCA2, see Table 4), we may conclude that NND does not directly influence RS. This was confirmed by the absence of a significant correlation between NND and RS ( $\mathrm{r}=0.057, \mathrm{P}=0.169)$ in O. insectifera. The populationyear variable was also retained within the models for both data subsets, and interactions were significant, indicating that RS varied significantly and differently between populations and years (Table 4).

In O. sphegodes, plant height and inflorescence size were significantly correlated, consequently, their variation was summarised using PCA, where the first axis contained $74.76 \%$ of the information (Table 3 ). The model with the best fit retained PCA1, indicating that the probability of pollination (RS) significantly increased with inflorescence size and plant height. Populationyear was also a significant factor (Table 4). The same model was selected for the 'RS greater than zero' dataset (Table 4). NND was not included in either of the models.

\section{Inter-population variation in reproductive success}

Patch geometry and population density were independent (O. fuciflora, $\quad \mathrm{r}=-0.2754, \quad \mathrm{P}=0.5091 ; \quad$ O. insectifera, $\mathrm{r}=0.0280, \quad \mathrm{P}=0.9311 ; \quad$ O. sphegodes,$\quad \mathrm{r}=0.5038$, $\mathrm{P}=0.3083$ ) for all of the three species studied. Population density and patch geometry (and year effect) were retained in the model (with the lowest AIC) for O. fuciflora, suggesting that decreasing density and more elongated patch shapes increased total RS in populations of this species (Table 5). Patch geometry (and year effect) had a similar significant consequence on RS in O. insectifera populations. Population density was not retained in the model with the lowest AIC. Finally, density was retained as the only significant variable explaining variation in RS in O. sphegodes populations (Table 5). Once again, an increase in population density led to a decrease in RS. A significant year effect was also detected for this species. RS decreased with population size, but this variable is not retained in any of the models (i.e. models had a better fit when including population density rather than size). 
Table 5. Population reproductive success in relation to population parameters including population size and density and patch geometry (only model with the lowest AIC, i.e. best fit, is shown).

\begin{tabular}{lcccr}
\hline source & $\begin{array}{l}\text { correlation } \\
\text { coefficient }\end{array}$ & df & $\chi^{2}$ & $\operatorname{Pr}>\chi^{2}$ \\
\hline Ophrys fuciflora & & & & \\
$\quad$ log(density) & -4.88 & 1 & 8.69 & 0.0032 \\
$\quad$ log(geometry) & -88.29 & 1 & 13.71 & 0.0002 \\
$\quad$ year & & 1 & 14.01 & 0.0002 \\
$\begin{array}{l}\text { Ophrys insectifera } \\
\text { log(geometry) }\end{array}$ & -22.94 & 1 & 4.17 & 0.0412 \\
$\quad$ year & & 1 & 3.91 & 0.0481 \\
$\begin{array}{l}\text { Ophrys sphegodes } \\
\text { log(density) }\end{array}$ & -32.96 & 1 & 19.77 & $<0.0001$ \\
$\quad$ year & & 1 & 8.97 & 0.0027 \\
\hline
\end{tabular}

Inter-annual variation in reproductive success

Although average RS of populations was generally higher in 2005 compared to 2006 for all three species (Table 1), the only significant difference between years in RS was for O. fuciflora (O. fuciflora: $t$-value $=2.73, \mathrm{P}=0.0342$, $\mathrm{df}=6 ; O$. insectifera: $t$-value $=0.85, \mathrm{P}=0.4210, \mathrm{df}=8$; O. sphegodes: $\quad t$-value $=0.12, \quad \mathrm{P}=0.4210, \quad \mathrm{df}=2)$. Although there was no significant difference in temperature between years during the flowering period of $O$. $f u$ ciflora and $O$. insectifera (May: $t$-value $=-0.67$, $\mathrm{P}=0.5067, \mathrm{df}=30$; June: $t$-value $=-0.68, \mathrm{P}=0.5010$, $\mathrm{df}=29$ ), there was significantly more daily sunshine in May 2005 compared to May $2006 \quad(t$-value $=2.07$, $\mathrm{P}=0.0470, \mathrm{df}=30)$. No significant differences were detected for the month of June $(t$-value $=-0.32$, $\mathrm{P}=0.7494$, df $=29$ ).

\section{DISCUSSION}

While numerous studies on RS have been carried out on food deceptive orchids, this is one of the first to test a set of individual, population and environmental variables in sexually deceptive orchid species. This study confirms that orchids in general, and non-rewarding species in particular, have very low rates of RS (Neiland \& Wilcock 1998; Tremblay et al. 2005). For example, a literature review on reproductive success in orchids found that fruit set was, on average, $27.7 \%$ compared to $63.1 \%$ in nectarless versus nectariferous European orchids, respectively (Tremblay et al. 2005). Ophrys fuciflora had the lowest RS of the three studied species $(4.02 \%$ capsule set) and O. insectifera the highest $(13.00 \%)$, although inter-population variation is quite high (Table 1). These values are similar to those cited in the literature, such as $8.7 \%$ (Neiland \& Wilcock 1998) and 5.4-27.1\% (Kullenberg 1950) for O. insectifera, and from $0.03 \%$ (Delpino cited in Darwin 1877 ) and $4.9 \%$ (Ayasse et al. 2000) to $21.1 \%$ (Neiland \& Wilcock 1998) in O. sphegodes. Although it could be argued that, given the high number of seeds within one orchid fruit, a high RS is not necessarily essential for these species, the number of individual plants with at least one fruit was also low $(15.33 \%$ for O. fuciflora; $38.59 \%$ for O. insectifera; $18.30 \%$ for O. sphegodes).

Our first hypothesis, that reproductive (or pollination) success would be highest towards the bottom of the orchid inflorescence and decrease towards the top, was confirmed in O. fuciflora and O. sphegodes. In food deceptive orchids this type of pattern has been attributed to foraging behaviour (i.e. pollinators tend to move upwards along an inflorescences in order to forage for nectar and may depart after unsuccessfully probing a few flowers, resulting in reduced pollination of flowers located towards the top) and/or depletion of naïve pollinators (i.e. flowers emerging in the latter half of the season would receive fewer pollinators, Tremblay et al. 2005), or to negative frequency-dependent selection for those flowers that open later in the season (when flower abundance is greater; Sabat \& Ackerman 1996). However, within inflorescence RS in O. insectifera showed an inverse trend, with flowers from the upper part of the inflorescence setting significantly more fruit than those from the lower parts. In sexually deceiving flowers, this type of inter-specific discrepancy may be due to differences in the patrolling behaviour of the pollinating male insects. For example, pollinator discrimination among floral heights has been reported in an Australian sexually deceptive orchid (Handel \& Peakall 1993; Peakall \& Handel 1993), as has pollinator preferences for flowers placed closer to the ground in relation to male patrolling behaviour (in Ophrys speculum, Paulus \& Gack 1980). Therefore, it is possible that male pollinators of O. fuciflora and O. sphegodes search for females closer to the ground (and consequently essentially pollinate flowers in the lower part of the inflorescence), while pollinators of $O$. insectifera search for females higher up. That $O$. insectifera is the tallest of the three species in this study may lend some support to this hypothesis. Unfortunately, too few pseudocopulatory events were observed to confirm or deny this hypothesis, and other factors such as degree of overlap between flowering period and male pollinator abundance are possible parameters of interest.

Higher RS in more visible plants (larger inflorescences and/or taller plants) in all three studied Ophrys species confirmed our second hypothesis, and was in agreement with results found in food deceptive orchids (increased RS in taller plants, e.g. O'Connell \& Johnston 1998; Kropf \& Renner 2005; Dickson \& Petit 2006) and plants with larger inflorescences (e.g. Johnson \& Nilsson 1999). In the case of the sexually deceiving orchid species used in this study, higher visibility should not necessarily be interpreted in terms of visual cues (although these remain important for the pollinator at close range), but rather in terms of olfactory cues. It can logically be assumed that plants with a larger number of flowers (inflorescence size) will produce more floral scent, as has been shown in other plant species (Valdivia \& Niemeyer 2006). Schiestl (2004) also demonstrated that orchids 
(Chiloglottis trapeziformis) emit larger quantities of 'pheromones' than the female insects (Neozeleboria cryptoides), resulting in increased attractiveness of the flower compared to the female for the male pollinator. Consequently, since larger inflorescences had more flowers open at a time than small inflorescences (D. Tyteca, unpublished results), we can expect plants with larger inflorescences to be more attractive to male pollinators than smaller inflorescences. Increased concentrations of floral scent may also increase the probability of a flower being detected by a male pollinator from a certain distance. This is of special interest in Ophrys species, where long-range (between $50 \mathrm{~cm}$ and several meters) attraction of the male pollinators is largely achieved by imitating the sex pheromones of the pollinator species (Schiestl et al. 1999, 2000). Additionally, as shown in O. sphegodes, odour was the most important factor releasing the pollinator copulatory behaviour (Schiestl et al. 2000) necessary for effective pollination. Therefore, larger inflorescences (larger odour plumes and higher substance concentrations) likely attract more male pollinators and increase pollination efficiency. It should be highlighted that, in this study, increased RS in larger inflorescences is not simply the result of pollinators visiting a higher number of flowers, since inflorescence size was a significant variable explaining RS in both data subsets, i.e. analyses comparing reproductive success versus failure and analyses comparing RS within plants having a RS greater than zero. Finally, these results do not necessarily contradict the within inflorescence results discussed above. First, we believe that inflorescence size, rather than plant height, better explains variation in RS because (i) when modelling RS without summing inflorescence size and plant height in the principal components, models including inflorescence size consistently had a better fit (higher likelihood) compared to models including plant height; and (ii) correlation coefficients were two- to eight-times greater for inflorescence size compared to plant height (results not shown). Second, there are numerous other constraints, beside pollinator selection, on plant height, including light (and other resource) limitation. Third, a study relating height to pollinator behaviour in the sexually deceptive orchid Chiloglottis trilabra (Peakall \& Handel 1993) concluded that pollinator-mediated selection cannot explain the precise height of the flowers but may contribute to the evolution of their relatively short height. Given these results, we suggest that pollinatormediated selection has resulted in generally shorter plants in O. fuciflora and O. sphegodes (compared to O. insectifera), with lower flower position within the inflorescence benefiting from increased pollination. Within these species, taller plants attract more pollinators, not necessarily because of their height but because they have larger inflorescences and consequently provide increased olfactory cues to their pollinators. Additionally, plants with larger inflorescences will increase their probability of pollination by increasing the likelihood of overlap between their flowering period (i.e. receptive flowers) and pollinator presence through a longer flowering period (D. Tyteca, unpublished results).

Both local density (NND, in the case of O. fuciflora) and population density (in the case of O. fuciflora and O. sphegodes) reduce RS in sexually deceptive orchids, confirming our third working hypothesis, and in agreement with results in nectar deceiving orchid studies (Fritz \& Nilsson 1994; Jacquemyn et al. 2002; Kropf \& Renner 2005; Tremblay et al. 2005; but see Wilcock \& Neiland 2002) where it is attributed to a pollinator limitation effect and pollinator learning. Although not retained in models with best fit (in favour of population density), population size was also negatively correlated to RS. Pollinator learning and consequent avoidance of deceiving flowers has been detected in Ophrys pollinators, as experimental tests with Andrena nigroaenea, a pollinator of O. sphegodes, have shown (a significant decrease in copulation attempts and pouncing events between the first and second presentation of the same flower was observed, Ayasse et al. 2000). However, several mechanisms have evolved in Ophrys flowers to avoid pollinator learning. First, variation in the pollinator-attracting olfactory recognition signals between flowers within an inflorescence may reduce pollinator learning. Indeed, a study in O. sphegodes found that $67 \%$ of the males that visited one flower of an inflorescence returned to visit a second (but different) flower of the same inflorescence (Ayasse et al. 2000). Additionally, O. sphegodes flowers, once pollinated, produce a substance imitating unreceptive breeding females (Schiestl \& Ayasse 2001) thereby redirecting pollinators to unpollinated flowers of the inflorescence. Consequently, since both population density and population size negatively influence RS in the studied Ophrys species, pollinator limitation is likely to be the main factor limiting RS, although pollinator habituation should certainly not be discarded as a potential limiting factor.

In this study, patch geometry also played an important role, with increased RS in the more elongated patches, likely due to a greater number of insect migrations into the patch. This may be a perimeter scaling effect, where the number of immigrants (in this case pollinating insects) is proportional to the length of the perimeter and therefore to the perimeter to area ratio (Englund \& Hamback 2007). In other words, holding area constant, a patch with a longer perimeter will likely have more organisms (i.e. pollinators) encounter it, resulting in increased pollination. Finally, although inter-annual RS is highly variable, results were consistent among years. Factors influencing insect activity, such as sunshine, likely explain the yearly differences in RS observed in this study.

To conclude, results from this study suggest that inflorescence size (and co-varying plant height) plays a key role in individual RS of sexually deceptive orchids. Our hypothesis is that larger inflorescences, producing larger odour plumes that travel further distances, attract a larger number of male pollinators. Moreover, higher concentrations of pseudocopulatory-inducing chemicals may lead to increased success of pollinia removal and/or 
deposition. Furthermore, larger inflorescences extend flowering period and increase the probability of temporal overlap with pollinator presence. Additional comprehensive pollinator behaviour and chemical studies should help confirm the hypotheses. On the other hand, pollinator selection for particular flower heights may be related to species-specific differences in pollinator patrolling behaviour, also resulting in position-dependent RS within an inflorescence. Given these results and the few pseudocopulatory events observed during the field season, we believe that pollinator limitation is more important than negative frequency-dependent selection in affecting population RS in the sexually deceptive orchids studied here.

\section{ACKNOWLEDGEMENTS}

We warmly thank J. Guyon, L. Gillmann and M. Duchateau for help with fieldwork, N. Schtickzelle for suggestions on statistical analyses, $\mathrm{H}$. Cotrim and N. Vereecken for discussions, and H. Jacquemyn and R. Wesselingh for helpful comments on the manuscript. We also thank nature conservation groups, local administrations and private owners for access to sites. Meteorological data were provided by the Royal Meteorological Institute of Belgium. This research benefited from a grant from the Belgian National Research Foundation (FRFC grant No. 2.4545.03 F, Brussels) to DT and MB, and a Leonardo da Vinci exchange programme grant to ASR, AC and DT. SV is a Fonds National de la Recherche (FNRS) post-doctoral fellow. This is publication BRC123 of the Biodiversity Research Centre.

\section{REFERENCES}

Akaike H., (1973) Information theory as an extension of the maximum likelihood principle. In: Petrov B.N., Csaki F. (Eds). Second International Symposium on Information Theory. Akademiai Kiado, Budapest, Hungary: 267-281.

Ayasse M., Schiestl F.P., Paulus H.F., Löfstedt C., Hansson B., Ibarra F., Francke W. (2000) Evolution of reproductive strategies in the sexually deceptive orchid Ophrys sphegodes: how does flower-specific variation of odor signals influence reproductive success? Evolution, 54, 1995-2006.

Calvo R.N. (1990) Inflorescence size and fruit distribution among individuals in 3 orchid species. American Journal of Botany, 77, 1378-1381.

Calvo R.N. (1993) Evolutionary demography of orchids intensity and frequency of pollination and the cost of fruiting. Ecology, 74, 1033-1042.

van der Cingel N.A. (1995) An Atlas of Orchid Pollination. European Orchids. A.A. Balkema Publishers, Rotterdam, 192 p.

Cozzolino S., Widmer A. (2005) Orchid diversity: an evolutionary consequence of deception? Trends in Ecology \& Evolution, 20, 487-494.

Darwin C. (1877) The Various Contrivances by Which Orchids are Fertilized by Insects. John Murray, London, 300 p.
Dickson C.R., Petit S. (2006) Effect of individual height and labellum colour on the pollination of Caladenia (syn. Arachnorchis) behrii (Orchidaceae) in the northern Adelaide region, South Australia. Plant Systematics and Evolution, 262, 65-74.

Dressler R.L. (1993) Phylogeny and Classification of the Orchid Family. Dioscorides Press, Portland, OR, 314 p.

Dukas R., Real L.A. (1993) Effects of recent experience on foraging decisions by bumble bees. Oecologia, 94, 244-246.

Englund G., Hamback P.A. (2007) Scale dependence of immigration rates: models, metrics and data. Journal of Animal Ecology, 76, 30-35.

Fritz A.L., Nilsson L.A. (1994) How pollinator-mediated mating varies with population size in plants. Oecologia, 100, 451-462.

Handel S.N., Peakall R. (1993) Thynnine wasps discriminate among heights when seeking mates - tests with a sexually deceptive orchid. Oecologia, 95, 241-245.

Internicola A.I., Juillet N., Smithson A., Gigord L.D.B. (2006) Experimental investigation of the effect of spatial aggregation on reproductive success in a rewardless orchid. Oecologia, 150, 435-441.

Jacquemyn H., Brys R., Hermy M. (2002) Flower and fruit production in small populations of Orchis purpurea and implications for management. In: Kindlmann P., Willems J.H., Whigham D.F. (Eds), Trends and Fluctuations and Underlying Mechanisms in Terrestrial Orchid Populations. Backhuys Publishers, Leiden: 67-84.

Jersáková J., Johnson S.D., Kindlmann P. (2006) Mechanisms and evolution of deceptive pollination in orchids. Biological Reviews, 81, 219-235.

Johnson S.D., Nilsson L.A. (1999) Pollen carryover, geitonogamy, and the evolution of deceptive pollination systems in orchids. Ecology, 80, 2607-2619.

Kindlmann P., Jersáková J. (2006) Effect of floral display on reproductive success in terrestrial orchids. Folia Geobotanica, 41, 47-60.

Kropf M., Renner S.S. (2005) Pollination success in monochromic yellow populations of the rewardless orchid Dactylorhiza sambucina. Plant Systematics and Evolution, 254, 185-197.

Kullenberg B. (1950) Investigations on the pollination of Ophrys species. Oikos, 2, 1-19.

Neiland M.R.M., Wilcock C.C. (1995) Maximization of reproductive success by European Orchidaceae under conditions of infrequent pollination. Protoplasma, 187, 39-48.

Neiland M.R.M., Wilcock C.C. (1998) Fruit set, nectar reward, and rarity in the Orchidaceae. American Journal of Botany, 85, 1657-1671.

Nilsson L.A. (1992) Orchid pollination biology. Trends in Ecology \& Evolution, 7, 255-259.

O'Connell L.M., Johnston M.O. (1998) Male and female pollination success in a deceptive orchid, a selection study. Ecology, 79, 1246-1260.

Paulus H.F. (2006) Deceived males - pollination biology of the Mediterranean orchid genus Ophrys (Orchidaceae). Journal Europäischer Orchideen, 38, 303-353. 
Paulus H., Gack C. (1980) Beobachtungen und Untersuchungen zur Bestäubungsbiologie südspanischer Ophrys - Arten. Jahresberichte des Naturwissentschaftichen Vereins in Wuppertal, 33, 55-68.

Paulus H., Gack C. (1990) Pollination of Ophrys (Orchidaceae) in Cyprus. Plant Systematics and Evolution, 169, 177-207.

Peakall R. (1990) Responses of male Zaspilothynnus trilobatus turner wasps to females and the sexually deceptive orchid it pollinates. Functional Ecology, 4, 159-167.

Peakall R., Handel S.N. (1993) Pollinators discriminate among floral heights of a sexually deceptive orchid - implications for selection. Evolution, 47, 1681-1687.

van der Pijl L., Dodson C.H. (1966) Orchid Flowers: Their Pollination and Evolution. University of Miami Press, Miami, FL, $214 \mathrm{p}$.

Sabat A.M., Ackerman J.D. (1996) Fruit set in a deceptive orchid: the effect of flowering phenology, display size, and local floral abundance. American Journal of Botany, 83, 1181-1186.

Salzmann C.C., Cozzolino S., Schiestl F.P. (2007) Floral scent in food-deceptive orchids: species specificity and sources of variability. Plant Biology, 9, 720-729.

Schiestl F.P. (2004) Floral evolution and pollinator mate choice in a sexually deceptive orchid. Journal of Evolutionary Biology, 17, 67-75.

Schiestl F.P., Ayasse M. (2001) Post-pollination emission of a repellent compound in a sexually deceptive orchid: a new mechanism for maximising reproductive success? Oecologia, 126, 531-534.

Schiestl F.P., Ayasse M., Paulus H.F., Löfstedt C., Hansson B.S., Ibarra F., Francke W. (1999) Orchid pollination by sexual swindle. Nature, 399, 421-422.

Schiestl F.P., Ayasse M., Paulus H.F., Löfstedt C., Hansson B.S., Ibarra F., Francke W. (2000) Sex pheromone mimicry in the early spider orchid (Ophrys sphegodes): patterns of hydrocarbons as the key mechanism for pollination by sexual deception. Journal of Comparative Physiology A-Sensory Neural and Behavioral Physiology, 186, 567-574.

Tremblay R.L., Ackerman J.D., Zimmerman J.K., Calvo R.N. (2005) Variation in sexual reproduction in orchids and its evolutionary consequences: a spasmodic journey to diversification. Biological Journal of the Linnean Society, 84, $1-54$.

Tyteca D., Róis A.S., Vereecken N.J. (2006) Observations on the pollination of Ophrys fuciflora by pseudo-copulating males of Phyllopertha horticola in northern France. Journal Europäischer Orchideen, 38, 203-214.

Valdivia C.E., Niemeyer H.M. (2006) Do pollinators simultaneously select for inflorescence size and amount of floral scents? An experimental assessment on Escallonia myrtoidea. Austral Ecology, 31, 897-903.

Wilcock C., Neiland R. (2002) Pollination failure in plants: why it happens and when it matters. Trends in Plant Science, 7, 270-277. 